13. $\mathrm{V}$ e $\mathrm{n}$ u s

\begin{tabular}{|c|c|c|c|}
\hline 1822 März I & $23^{\text {h } 24} 34^{\prime \prime}, 61$ & I R. & $+5^{\circ} 16^{\prime} 2,2$ \\
\hline 3 & 232031,54 & 一 & $+5218,6$ \\
\hline 5 & 231611,15 & - & $+44312,2$ \\
\hline 13 & $22 \quad 56 \quad 22,33$ & II R. & $+2272,7$ \\
\hline 14 & $22 \quad 54 \cdot 25,72$ & - & $+2833,8$ \\
\hline 15 & $\begin{array}{lll}22 & 52 & 34,79\end{array}$ & - & + I 4952,0 \\
\hline
\end{tabular}

Sonnenbeobachtungen.

\begin{tabular}{|c|c|c|}
\hline 1822 März I & $22^{h} 47$ & 24,65 \\
\hline 3 & 2254 & 52,80 \\
\hline 5 & 232 & 19,42 \\
\hline 14 & 2335 & 28,10 \\
\hline 15 & $23 \quad 39$ & 7,72 \\
\hline 16 & 2342 & 46,81 \\
\hline
\end{tabular}

Um die Zeit der Zusammenkunft der. Venus mit der Sonne war der Himmel fortwährend bewölkt; sonst hätte ich den Planeten olne Unterbrechung beobachten können, indem ich eine vollständige Beschirmung des Instruments und der Pfeiler eingerichtet hatte. Da dieses früher nicht so der Fall war und ich überzengt bin, dafs die Beobachtungen ohne Beschirmung ganz unzuverlässig werden, so habe ich erst seit kurzer Zeit angefangen, die unteren Planeten anhaltender zu beubachten; mich früher dazu in den Stand zu setzen habe ich unterlassen, da ich die Beobachtungen der Circumpolarsterne, welche, der Untersuchung der Reductionselemente wegen, nothwendig waren, nicht durch andere forlgesetzte Beobachtungsreihen unterbrechen wollte.

Bessel.

Auszug aus einem Schreiben des Herrn Professor und Ritter Bessel an den Herausgeber:

Die Polhöhe der Sternwarte wurde friiher $=54^{\circ} 42^{\prime} 50^{\prime \prime}, 0$ anıcnommen; allein eine lieihe von Beubachtungen $\alpha$ Ursae min. bei der Zenithdistanz von $36^{\circ}$, welche mir in jeder Hinsicht sehr sicher zu seyn schesnt, gah $57^{\circ} 42^{\prime} 50^{\prime \prime}, 276-$ $0,452 \triangle \delta$, wo $\triangle \delta$ die Verbesserung der Declination meiner Polarsterntafeln bedeutet.

Gegenwärtig habe ich eine kleine Verbesserung der Strahlenbrechung als nothwendig erkannt und $\triangle \delta=-0^{\prime \prime}, 339$ gefunden; wendet man beide an, so folgt daraus die Polhöhe $54^{\circ} 42^{\prime} 50^{\prime \prime}, 24$.

Dagegen geben mir äusser'st zahlreiche, mit dem Meridiankreise von. Reichenbach gemachte Beobachtungen, $\mathrm{n}$ ach der Untersuchung aller Febler und Verbesserungen, deren Müglichkeit mir vorhanden zu seyn scheint, die Pollöhe

$$
54^{\circ} 42^{\prime} 50^{\prime \prime}, 52
$$

so dafs zwischen beiden Bestimmungen noch ein Unterschied von $0^{\prime \prime}, 28$ ist, welcher nicht ganz in den Grenzen der wahrscheinlichen Fehler liegt. Ich glaube nicht, dafs dieser Unterschied ein bestimmter Beweis noch vernachlässigter be:tändiger Fehler ist, aber ich weifs auch nicht welcher Bestimmung der Vorzug gebührt. Meines Erachtens mülste daher das Miftel $54^{\circ} 42^{\prime} 50^{\prime \prime}$, 4 genommen werden.

\section{Bessel.}

\title{
Auszug aus einem Briefe des Herrn Professor Littrows in Wien an den Herausgeber.
}

Ich habe Ihnen letzthin meine Sternbedeckungen vom Monde bis $26^{\text {sten }}$ Februar 1822 geschickt. Diese letzten Tage bin ich durch gute Witterung sehr begünstigt worden, und habe den $27^{\text {sten }}$ Februar sechs, den $28^{\text {sten }}$ zwey, den

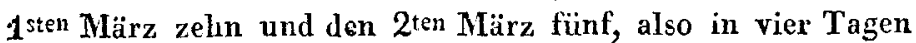
drey und zwanzig Bedeckungen erhalten; auch diese werde ich nächstens zúschicken. Wenn nux andere Astronomen. sie auch beobachtet hätten, damit wir correspondirende erhielten. Wäre es nicht möglich, itzt, wo ihre Zeitschrift ein so gutes Miltel dazu anbietet, die Herrn alle einzuladen, an gewissen festbestimmien Tagen und Siunden a 11 e Sternbedeckungen zu beobachten, die Slatt haben? z. B. die ersten zehn Tage nach dem Neumonde von Sonnenuntergang bis fünf oder sechs Stunden nach Sonnenuntergang oder dergleichen. Wir würden auf diese Art eine Menge nülzlicher Beolachtungen erhalten, ohne dafs sie erst alle voraus berechnet werden dürfen. Thun Sie doch etwas fïr diese gute Sache, und rechnen Sie auf meine Mitwirkung.

Littrow. 